\section{Rethinking peer review}

Your editorial of Jan. $12^{1}$ is absolutely right about the need for timely peer review, especially for manuscripts with potential public health significance. Timely peer review is important, but may not address the issue. The problem is with peer review itself, at least in relation to research dissemination that has significant public health impact. Most peer reviews consist of two to three reviewers and the editorial staff of the journal - at most 10-20 people in the world. Yet they are tasked with deciding matters that affect the lives of millions. What can be done? Would it be possible for journals to post potentially important manuscripts on the web before peer review? This way, instead of 20 people having knowledge of its contents and judging its worth, perhaps 200 , or 2000 people will. The ultimate decision will still rest in the hands of the editors. Policy makers can also judge for themselves or pass it to their technical staff or ad hoc expert groups for review. This is, of course, not perfect, but is an improvement over the current practice.

\section{Kue Young MD PhD}

Professor, Dalla Lana School of Public Health University of Toronto, Toronto, Ont.

\section{REFERENCE}

1. Stanbrook MB, Hébert PC. Disseminate timesensitive research faster. CMAJ 2010;182:9.

For the full letter, go to: www.cmaj.ca/cgi/eletters /182/1/9\#265351

DOI:10.1503/cmaj.110-2025

\section{Missing the boat}

I must disagree with the conclusion drawn by Cameron and colleagues. ${ }^{1}$ Technology is not static, and can never be assumed to be final. One should not focus on such a variable as the cost of a blood glucose strip, as it is a technology that will eventually become obsolete. Therefore, to suggest simply that it is not cost-effective to measure blood glucose daily unless the cost of strips decreases implies a fixation on the present while sacrificing good diabetic control. Rather, one should actively encourage a change in the status quo and even propose an enticement to create a cheaper alternative device.

\section{Elie Sarraf MDCM BEng}

Medical resident, St. Mary's Hospital

Centre, Montréal, Que.

\section{REFERENCE}

1. Cameron C, Coyle D, Ur E, et al. Cost-effectiveness of self-monitoring of blood glucose in patients with type 2 diabetes mellitus managed without insulin. CMAJ 2010;182:28-34.

For the full letter, go to: www.cmaj.ca/cgi/eletters /182/1/28\#265030

DOI:10.1503/cmaj. 110-2022

\section{The author responds:}

Re: "Missing the boat."' The CADTH findings $s^{2}$ underline the importance of understanding the cost effectiveness of blood glucose test strips to the sustainability of contemporary diabetes care. The number of Canadians diagnosed with diabetes almost doubled, to close to 2.3 million, in the past decade, and another 200000 people learn they have the disease each year. The technology with respect to self-monitoring of blood glucose has basically been static for two decades - and is not likely to be replaced in the near future, making effective use of this technology crucial to appropriate allocation of resources. Further information, reports and supporting tools may be found at www.cadth.ca/smbg.

Chris Cameron MSc

Canadian Agency for Drugs and Technologies in Health, Ottawa, Ont.

\section{REFERENCE}

1. Sarraf E. Missing the boat [letter]. CMAJ 2010; $182 ; 281$.

2. Cameron C, Coyle D, Ur E, et al. Cost-effectiveness of self-monitoring of blood glucose in patients with type 2 diabetes mellitus managed without insulin. CMAJ 2010;182:28-34.

For the full letter, go to: www.cmaj.ca/cgi/eletters /182/1/28\#267079

DOI:10.1503/cmaj. 110-2023

\section{First Nations health data}

The difficulties in collecting and accessing relevant injury, health-related data in Aboriginal and First Nations communities in Canada are well documented. ${ }^{1}$ But the necessity for accurate and timely data is clear. Limited information, combined with few dedicated resources and the absence of targeted programs, impedes disease prevention activities in these communities. The available limited literature shows that addressing the complex range of health problems in disadvantaged Aboriginal or First Nation communities requires considerable work in capacity building with local communities to address their overall public health issues. It is time to provide honest leadership with sufficient resources and the evidence base for a national action plan on surveillance, prevention and control of communicable and noncommunicable diseases, specifically, mental health disorders, violence and injuries.

\section{Ediriweera Desapriya $\mathbf{P h D}$}

Centre for Community Child Health

Research and Department of Pediatrics,

Faculty of Medicine, University of British

Columbia, Vancouver, BC

\section{REFERENCE}

1. Silversides A. Improved Aboriginal child health data collection urged. CMAJ 2010;182:E47.

For the full letter, go to: www.cmaj.ca/cgi/eletters /182/1/E47\#266754

DOI:10.1503/cmaj.110-2028

\section{Letters to the editor}

In submitting a letter, you automatically consent to have it appear online and/or in print. All letters accepted for print will be edited by $C M A J$ for space and style. Most references and multiple authors' names and full affiliations will appear online only. (The full version of any letter accepted for print will be posted at cmaj.ca.) 